\title{
Effect of exogenous hormones on ovulation synchronization and conception rate of achai cattle
}

\begin{abstract}
The study was conducted to evaluate OvSynch protocol for synchronization of ovulation in Achai cows at Livestock Research and Development Station Surezai, Peshawar. A total 40 Achai cattle were subjected to OvSynch protocol. All the selected animals exhibited normal subsequent genital health as assessed by clinical examination of reproductive organs. Treated animals were inseminated at fixed time of $16 \mathrm{hrs}$ after 2nd injection of Gonadotropic Releasing Hormone $(\mathrm{GnRH})$ with or without estrus detection. The animals were classified as Nulliparous $(n=2)$, Primiparous $(n=9)$ and Pluriparous $(\mathrm{n}=29)$ based on previous history of pregnancies and parturitions. Results suggested that overall conception rate achieved was $45 \%$ with 18 animals conceiving with this protocol. One of 2 animals classified as Nulliparous was declared pregnant giving a conception rate of $50 \%$. Three out of nine animals, classified as Primiparous, conceived giving a conception rate of $33.33 \%$, while $48.27 \%$ conception rate was achieved in animals classified as Pluriparous with 14 animals conceiving among 29 animals
\end{abstract}

Volume 7 Issue 3 - 2018

Hayaz Uddin, ${ }^{2}$ Muhammad Nauman ul Islam,' Arsalan Ali Shah,' AbdurRaziq,' Muhammad Sohail,' Imtiaz Ali Shah,' Inamullahwazir,' SubhanUllah²

'Livestock Research and Development Station, Pakistan ${ }^{2}$ Directorate General (Research), Livestock and Dairy Development, Pakistan

Correspondence: Hayaz Uddin, Directorate General (Research), Livestock and Dairy Development, K.P.K, Peshawar, Pakistan,Tel 0303-8260828, Email drhayaz13@yahoo.com

Received: November 22, 2017 | Published: June 20, 2018

Keywords: achai cattle, ovsynch protocol, synchronization

\section{Introduction}

Achai are small-sized cattle breed found in Khyber Paktunkhwa province and are famous for its high resistant to extreme environmental conditions. The home tract of Achai cattle are district Dir, Swat, Bajaur Agency and extend on the west to adjoining parts of Afghanistan. These cows are suitable for mountainous terrain and can resist cold as well as warm climate. It has a small body and thus needs little feed. It is a dairy and light draught breed that can thrive under scarce fodder availability and can produce adequately under a hilly and sub-hilly subsistence production setup. ${ }^{1}$ Achai is yet undocumented but well-adapted cattle breed of the Hindu Kush Mountains of northern Pakistan. ${ }^{2}$ Achai cows also have a better reproductive performance than other cattle breeds in Pakistan. ${ }^{3}$ The goal to develop a hormonal synchronization program that could overcome the problems and limitations associated with visual detection of estrus in dairy cattle was realized in 1995 with the publication of a hormonal synchronization protocol that combined $\mathrm{GnRH}$ and PGF $2 \alpha$ to control ovarian physiology and is now commonly referred to as the OvSynch protocol. ${ }^{4}$ The OvSynch protocol synchronizes follicular development, luteal regression and ovulation so artificial insemination can be conducted at a fixed-time without the need of estrus detection, commonly referred to timed artificial insemination (TAI). Subsequent studies that repeated this work soon verified the results of the original publication, ${ }^{5,6}$ and dairy producers and veterinarians began to implement the OvSynch protocol as a tool for reproductive management on commercial cattle farms.

Optimum fertility in Achai cows can be achieved by a holistic approach including improved management, nutrition and application of advanced reproductive technology such as OvSynch protocol. OvSynch is one of the most classical and widely known systems of breeding for reproductive management in postpartum cows. ${ }^{6}$ The protocol consists of two injections of $\mathrm{GnRH}$ analogue separated by a single administration of PGF $2 \alpha$. The ovulation is precisely synchronized in dairy cows and usually occurs approximately $26-32$ hrs after second GnRH injection. Thus, a timed insemination at 14-20 hours after second injection of GnRH results in a high probability of successful conception. ${ }^{7}$ In most of ovulation synchronization schemes GnRH is used to control follicular development and induce ovulation of a dominant follicle with PGF2 $\alpha$ as a mean for luteal regression.

\section{Materials and methods}

A total of 40 Achai cows maintained at Livestock Research \& Development Station Surezai, Peshawar including 10 Achai cows of Livestock Research \& Development Station Swabi was utilized for the present study. All experimental animals were fed under stall feeding with green fodder, wheat straw and concentrate feed (shandar Vanda) throughout the year as per routine practices at the station. All the selected animals exhibited normal subsequent genital health as assessed by clinical examination of reproductive organs and found apparently free from genital infection. The animals were classified as Nulliparous, Primiparous and Pluriparous based on previous history of pregnancies and parturitions. The experimental animals were treated with initial intramuscular injection of $50 \mu \mathrm{g}$ Lecirelin acetate, a synthetic analogue of GnRH (Dalmaralin ${ }^{\circledR} 2 \mathrm{ml}$ ) on the first day of the trial (Day 0 of OvSynch protocol), 7 days later $25 \mathrm{mg}$ Dinoprost, a naturally-occurring prostaglandin F $2 \alpha$ (Inj. Lutalyse ${ }^{\mathrm{TM}}$ $5 \mathrm{ml}$ ) was injected intramuscularly. One or two days later (day 9 or 10 of OvSynch protocol) animals received second injection of $50 \mu \mathrm{g}$ Lecirelin acetate $(\mathrm{GnRH})$. All the experimental animals were inseminated at fixed time (FTAI) $16 \mathrm{hrs}$ after second GnRH injection with or without estrus sign detection. Pregnancy diagnosis was carried out through examination per rectum between day 60 and 75 after artificial insemination. Differences of significance in variables were determined using sample T-TEST using SPSS version 19.0. The conception rate was determined as the proportion of animals that got 
conceived from those that were inseminated using the synchronization protocol.

\section{Results and discussion}

Overall conception rate achieved was $45 \%$ with 18 animals conceived with this protocol. One of 02 animals, classified as Nulliparous $(\mathrm{N})$, was declared pregnant giving a conception rate of 50 $\%$. Three out of 9 animals, classified as Primiparous (PR), conceived giving a conception rate of $33.33 \%$, while 14 animals conceived among 29 classified as Pluriparous (PL), with $48.27 \%$ conception rate. The response of cyclic animals to OvSynch treatment and conception was positive as compared to acyclic animals. This finding is in line with Klindworth et al., ${ }^{8}$ who reported similar positive effect of OvSynch treatment in cyclic cows based on plasma progesterone concentration. Present findings are in accordance with previous findings of Pursley et al., ${ }^{9}$ Cordoba \& Fricke, ${ }^{10}$ who reported conception rate ranging from 29 to $60 \%$ after OvSynch treatment. However, many workers ${ }^{8,11}$, reported lower conception rate in dairy cows after OvSynch treatment.

Using the conventional artificial insemination in cyclic Achai cows upon estrous detection in our previous trials ${ }^{12-16}$ the first service conception rate recorded was 63.12 percent and numbers of services per conception were $1.45 \pm 0.11$, which was in line with Seleem et al., ${ }^{17}$ who reported the first service conception rate 71.01 percent and $1.48 \pm 0.05$ numbers of services per conception. Any synchrony protocol should be used considering that reflects the complexities of interactions among management skills, milk production, environment and nutrition. Estrous synchronization is an important tool for increasing the rate of implementation of artificial insemination in cattle ${ }^{18-23}$ the methods for estrous synchronization should be relatively simple to employ and should be robust so that they can be applied under a variety of management conditions.

\section{Conclusion}

From the present study OvSynch protocol has positive effect on the conception rate of Achai cattle under better management condition. Achai is a small cattle breed in Pakistan. It is a multipurpose animal genetic resource, being reared both as dairy and draught animal. The constant threat to Achai breed is found in its indiscriminate breeding due to lack of Achai breeding bulls, less attractive milk production and lack of information about their other qualities such as excellent fertility, short service period, short calving interval, persistent milk production, less feed requirement and disease resistant, thus causing dilution of Achai and its adaptive characteristics. Documenting the productive, reproductive characteristics and selecting Achai cattle with better productive and reproductive performances can help in further improving the breed's traits and increase its outputs. ${ }^{12}$

\section{Acknowledgements}

None.

\section{Conflict of interest}

Author declares there is no conflict of interest.

\section{References}

1. Khan, MS, Rehman Z, Khan MA, et al. Genetic resources and diversity in Pakistani cattle. Pak Vet J. 2008;28(2):95-102.

2. Saleem M, Rahim I, Rueff H, et al. Morphological characterization of the Achai cattle breed under sedentary and transhumant farming system in Pakistan. Animal Genetic Resources. 2013;52:83-90.

3. Saleem M, Rahim IU, Rueff H, et al. Effect of management on reproductive performances of the Achai cattle in the Hindukush (Northern Pakistan). Trop Anim Health Prod. 2012;44(6):1297-1302.

4. Pursley JR, Mee MO, Wiltbank MC. Synchronization of ovulation indairy cows using PGF2 $\alpha$ and GnRH. Theriogenology. 995;44(7):915923.

5. Burke CR, Mussard ML, Grum DE, et al. Effects of maturity of the potential ovulatory follicle on induction of estrus and ovulation in cattle with estradiol benzoate. Anim. Reprod Sci. 2001;66(3-4):161-174.

6. Pursley JR1, Wiltbank MC, Stevenson JS, et al. Pregnancy rates per artificial insemination for cows and heifers inseminated at a synchronized ovulation or synchronized estrus. J Dairy Sci.1997;80(2):295-300.

7. Peters AR, Mawhinney I, Drew SB, et al. Development of a gonadotrophin releasing hormone and prostaglandin regimen for the planned breeding of dairy cows. Ve. Rec.1999;145(18):516-521.

8. Klindworth HP, Hoedemaker M, Burfeindt D, et al. Synchronization of ovulation (OvSynch) in high producing dairy cattle herds. 1. Fertility parameter, body condition score and plasma progesterone concentration.Dtsch Tierar.Wochen, 2001;108(1):1-9.

9. Pursley JR, Silcox RW, Wiltbank MC. Effect of time of artificial insemination on pregnancy rates, calving rates, pregnancy loss, and gender ratio after synchronization of ovulation in lactating dairy cows. J Dairy Sci. 1998;81(8):2139-2144.

10. Cordoba MC, Fricke PM. Evaluation of two hormonal protocol for synchronization of ovulation and timed artificial insemination in dairy cows managed in grazing - based dairies'. Dairy Sci. 2001;84(12):2700 2708 .

11. Schmitt EJ, Diaz T, Drost $\mathrm{M}$, et alUse of gonadotropin releasing hormone agonist or human chorionic gonadotropin for timed insemination in cattle. J Anim Sci. 1996;74(5):1084-1091.

12. Uddin H, HU Khan, MI Khan, et al. Productive and Reproductive Performance of Achai Cattle maintained at Livestock Research \& Development Station Surezai Peshawar, Pakistan JAnim Health Produc. 2014;22(1):2014.

13. Ambrose JD, Kastelic JP, Rajamendran R. Pregnancy rates in dairy cows after $\mathrm{GnRH}$ treatment at 7,14 or 7 and 14 days after timed insemination. Canadian J Anim Sci. 2000;80:755.

14. Cartmill JA, El-Zarkouny SZ, Hensley BA, et al. Stage of cycle, incidence and timing of ovulation and pregnancy rates in dairy cattle after three timed breeding protocol. J Dairy Sci. 2001;84(5):10511059.

15. Geary TW, Whittier JC, Downing ER, et al. Pregnancy rates of postpartum beef cows that were synchronized using synchro- B or Ovsynch protocol. J Anim Sci. 2001;76(6):1523-1527.

16. Macmillan KL, Segwagwe BV, Pino CS, et al. Associations between the manipulation of patterns of follicular development and fertility in cattle. Anim Reprod Sci. 2003;78(3-4):327-344.

17. Saleem M, Inam Ur-Rahim, Henri Rueff. Mountain cattle breed for coping with climate change: needs for conserving and reintroducing the Achai in the Hindu Kush Mountains of northern Pakistan. Conference on International Research on Food Security: Zurich; 2013. p. 14-16.

18. Lucy MC, Billings HJ, Butler WR, et al. Efficacy of an intravaginal progesterone insert and an injection of PGF2 $\alpha$ for synchronizing estrus and shortening the interval to pregnancy in postpartum beef cows, peripubertal beef heifers, and dairy heifers. J Anim Sci. 2001;79(4):982- 
995 .

19. Mann GE, Lamming GE, Robinson RS, et al. The regulation of interferonô production and uterine hormone receptors during early pregnancy. J Reprod Fertil. 1999;54:317-328.

20. Murugavel K, Yániz JL, Santolaria P, et al. Luteal activity at the onset of a timed insemination protocol affect reproductive outcome in postpartum dairy cows. Theriogenology. 2003;60(3):583-593.

21. Santos JE, Thatcher WW, Pool L, et al. Effect of human chorionic gonadotropin on luteal function and reproductive performance of highproducing lactating Holstein dairy cows. J Anim Sci. 2001;79(11):2881-
2894.

22. Stevenson JS, Portaluppi MA, Tenhouse DE, et al. Interventions after artificial insemination: conception rates, pregnancy survival, and ovarian responses to gonadotropin-releasing hormone, human chorionic gonadotropin, and progesterone. J Dairy Sci. 2007;90(1):331-340.

23. Vasconcelos JL, Silcox RW, Rosa GJ, et al. Synchronization rate, size of ovulatory follicle and pregnancy rate after synchronization of ovulation beginning on different days of the estrous cycle in lactating dairy cows. Theriogenology. 1999;52(6):1067-1078. 